\title{
Evaluating the Topaz ERP System Effectiveness Using a System Integrative Approach
}

\author{
Emmanuel Peters \\ Computer Science and Information Technology \\ Accra Institute of Technology \\ Accra, Ghana
}

\author{
George Kwamina Aggrey \\ Computer Science and Information Technology \\ University of Cape Coast \\ Cape Coast, Ghana
}

\begin{abstract}
ERP systems selection, adoption and implementation are a complex, lengthy and costly process which tends to face serious failure. Higher Education Institutions are rapidly adopting and implementing these systems despite some implementation failures that have been reported elsewhere. Thus, it is essential to perform post-implementation assessment of these systems to evaluate how much they have succeeded or failed in achieving their predetermined objectives. The purpose of this paper is to evaluate the effectiveness of topaz ERP systems in higher education institutions using a system integrative approach. Using a mixed-method research, data for quantitative and qualitative were collected and analyzed using partial least square - structural equation modeling (PLS-SEM) and inductive thematic analysis. The findings of the study revealed that financial perspective, customer/stakeholder perspective, and system quality perspective have significant influence or positive association with the effectiveness of topaz ERP systems evaluation in the Ghanaian higher education. The findings again, revealed that internal business process and learning and growth perspectives have no significant influence with the effectiveness of topaz ERP systems in Ghanaian context. Studies about the evaluation of ERP systems effectiveness in the Ghanaian higher education are rare. Available studies in Ghana have focused on the implementation issues and use only.
\end{abstract}

Keywords: ERP systems, Evaluation, ERP effectiveness, Balanced Scorecard, ISO 25010 Model

\section{INTRODUCTION}

The information system (IS) field over the years has seen a tremendous growth both in practice and research. The growth of information systems (IS) has played an essential role in improving the operations of business organizations and institutions. In this respect, ERP (Enterprise Resource Planning) systems come as integrated information systems, in order to plan, control and direct the business functions of an organization. Many studies have shown that ERP systems are effective in improving the operations of business organizations [3][19][27] while others have suggested otherwise [1][2][26]. Many different types of ERP systems such as SAP, Oracle, Baans and Microsoft have all been researched and evaluated for their effectiveness in organizations. The topaz ERP system which has also gained some popularity among higher education institutions (HEIs) is yet to be researched and evaluated. There is no literature that has reported about the effectiveness of topaz ERP system in HEIs. The high cost of implementing these systems needs to be evaluated in order to ascertain their effectiveness. Hence, (due to the popularity of the topaz system) there is the need to evaluate the effectiveness of the topaz system in order to justify its continuous use in the higher education institutions.

\section{TOPAZ ERP SYSTEMS}

Topaz as an ERP systems vendor has been delivering Microsoft Dynamics NAV and its successor Dynamics 365 Business Central (BC) to New Zealand organizations for over twenty years. Topaz ERP systems vendors have consistently delivered high quality, reliable and cost-effective solutions, on time and on budget. Other products that are delivered by topaz include topaz GEMS, Jet Global, Continia, Dynamics eshop, BI360, Scapta and Sana [35].

\subsection{Microsoft Dynamics 365 Business Central (BC)}

Business Central is the most popular ERP system in the world with over 2 million users worldwide. It offers powerful ERP Technologies to a broad industry base, and is flexible enough to be customized to any business and its unique requirements. It is an all-in-one business management solution that is easy to use and adapt, helping you connect your business and make smarter decisions. This all-in-one ERP business management solution helps organizations and institutions to connect their financials, sales, services, and operations together in order to streamline business processes, improve customer interactions, and make better decisions. Some features of Microsoft Dynamics 365 Business Central (BC) include:

- Manage your Financials: Make informed decisions, Accelerate financial close and reporting, Improve forecast accuracy.

- Automate your Supply Chain: Optimize stock levels, Avoid lost sales and reduce shortages, Maximize profitability.

- Sell Smarter: Deliver value at every touch point, Boost sales productivity, Deliver exceptional service.

- Optimize Project Management: Stay on budget, Plan with precision, Analyze project performance.

- Delivering Operational Excellence: Manage forecasting to fulfillment, Run your warehousing efficiently, Reach optimal output levels

\subsection{Microsoft Power Platform}

Microsoft Power Platform is an integrated application platform that combines Power BI, PowerApps, and Microsoft 
Flow. This system improves productivity across business organizations and institutions.

\subsection{Topaz Gems}

These are bespoke solutions of topaz developed in-house and are designed to deliver additional functionality and efficiencies beyond the scope of the core technologies provided. The main features of these bespoke solutions include Advanced Allocations, Advanced Bank Reconciliation, Advanced Fixed Assets, Code Combination Validation, Electronic Funds Transfer (Direct Credits), Direct Debits, Purchase Line Approvals, Property Management, Contract Management, Job/Project Reporting Codes, Recurring Invoices, Landed Cost.

\subsection{Microsoft Dynamics NAV}

Some services provided by Microsoft Dynamics NAV include:

- License optimization

- Onsite/Off site training

- NAV performance optimization

- Custom development

- Hosting

- Problem Resolution

\subsection{Continia}

Continia delivers an end-to-end solution for document recognition, invoice approval and digital archiving documents. Automate every step of your daily invoice processing - from receiving and registering the documents to retrieving them again later for auditing and reporting. Some unique features of this system include Payment Management 365, Expense Management 365, Document Output 365, and MobilePay Invoice 365.

\subsection{Sana}

Sana integrates effortlessly with Business Central to deliver a first class e-commerce solution. Using Sana commerce can turn Dynamics 365 Business Central into the driver of your ecommerce experience, giving you the flexibility and web store features you need - without the added complexity of a long implementation process.

\section{APPLICATION OF THE TOPAZ ERP SYSTEM}

From institutional point of view, it is currently being used in the University of Cape Coast. The topaz ERP system is used at the administration section of the university, and it is one of the topaz Gems designed and developed in-house. Since the topaz ERP system (an accounting software system), has been adapted by the University of Cape Coast to manage its finance and human resource departments. At the finance department, topaz software system is used to manage the payroll, cash inflows and cash out-flows, manage purchases and the store section of the university etc. In the human resource department, its being used to manage employees' records and information, salaries of employees and retirement packages etc.

The topaz system for the past three years of its use in the university has not seen any major setback. Even though as a system there may be some challenges, care has been taken to address those challenges when they arise. Nevertheless, evaluations must be done frequently to unearth challenges so that managements can find appropriate solutions to improve the system.

\section{THEORETICAL BACKGROUND OF THE STUDY}

The framework for this study is an adopted analytic framework of [28], which integrates both BSC framework and ISO 25010 Model to evaluate the effectiveness of ERP systems in HEIs. In their framework, five perspectives or constructs (representing independent variables) and one construct (representing dependent variable) were used to evaluate the effectiveness of ERP systems in HEIs. Twentysix (26) indicators were also proposed in their framework to measure these five perspectives or constructs.

\subsection{Balanced Scorecard (BSC) Framework}

The Balanced Scorecard (BSC) framework, introduced by [22], is well-known as one of the most popular methods in performance evaluation. The cardinal purpose of BSC is to replace or overcome the inadequacies of the traditional financial-based performance measurement tools. The first and the original use of the BSC framework was performance measurement [22]. When BSC is used to measure performance, the focus is on the four performance metricsfinancial, learning and growth, customer, and internal process metrics. By evaluating the four metrics, the BSC assists companies to track all the important aspects of a company's strategy as well as achieve continuous improvement of partnership and teamwork [8]. The BSC framework [21] presents the four perspectives and their measuring indicators. These four perspectives were defined by Kaplan in question forms as follows:

- Financial Perspective (How do the organization look to shareholders?)

- Customer Perspective (How do customers see the organization or the institution?)

- Internal Business Process (What must we excel at?)

- Innovation and Learning Perspective (Can we continue to improve and create value?)

\subsection{ISO 25010 Model}

The ISO 25010 is an international standard for software quality evaluation. It was originally presented in 1991 and has been revised and extended in 2007, 2011 and 2017. According to [20], the ISO 25010 quality model presents three aspects of software quality which address the internal quality, external quality and quality in use. Therefore, this model evaluates the quality of software in term of the external and internal software quality and their connection to quality attributes. In this respect, the model presents such quality attributes as a hierarchical structure of characteristics and subcharacteristics. The highest levels consist of eight (8) characteristics that are further divided into thirty- one (31) sub-characteristics on the lowest levels. The main significance of this model is that the model can be applied to the quality of any software product [12]. 


\section{RESEACH FRAMEWORK AND HYPOTHESES DEVELOPMENT}

Here, the six (6) adopted constructs identified in the proposed analytic framework of [28] will be discussed together with their measuring indicators. These six constructs or variables have been adopted to assess the effectiveness of ERP systems in HEIs.

\subsection{Financial Perspective (FP)}

This perspective according to [22] involves a question such as: To succeed financially, how should we appear to our shareholders? In the views of [31], the goal of ERP systems evaluation with respect to financial perspective is to reduce cost and improve return on investment (ROI). Various studies [6][9][27][31] have used financial perspective in the evaluation of ERP systems effectiveness.

This study has adapted the financial performance indicators of [8] for the evaluation of topaz ERP systems effectiveness in HEIs. In conclusion, financial perspective is a critical component for the evaluation of topaz ERP systems effectiveness in HEIs. We can therefore, agree that, the effectiveness of topaz ERP systems in HEIs can be affected (evaluated) by the financial perspective. We therefore, propose the following hypothesis:

H1: Financial perspective has a significant influence on topaz ERP system effectiveness in HEIs

\subsection{Customer/Stakeholder Perspective (CP)}

In [23], the researchers explained the customer/stakeholder perspective in a question form as: Are we delighting (or at least satisfying) our customers/stakeholders? Various studies [6][9][27][31] have used customer/stakeholder perspective in the evaluation of ERP systems effectiveness.

This study has adapted the customer/stakeholder performance indicators of [8] for the evaluation of topaz ERP systems effectiveness in HEIs. In conclusion, customer/stakeholder perspective is a critical component for the evaluation of topaz ERP systems effectiveness in HEIs. Hence, we agree that, the effectiveness of topaz ERP systems in HEIs can be affected (evaluated) by the customer/stakeholder perspective. We therefore, propose the following hypothesis:

$\mathrm{H}$ 2: Customer/stakeholder perspective has a significant influence on topaz ERP system effectiveness in HEIs

\subsection{Internal Business Process Perspective (IBPP)}

This [23] explains the internal business process perspective also in a question form as: Are we doing the right things? And doing things right? Various studies [6][9][27][31] have used internal business process perspective in the evaluation of ERP systems effectiveness.

This study has adapted the internal business process performance indicators of [8] for the evaluation of topaz ERP systems effectiveness in HEIs. In conclusion, internal business process perspective is a critical component for the evaluation of topaz ERP systems effectiveness in HEIs. Hence, we agree that, the effectiveness of topaz ERP systems in HEIs can be affected (evaluated) by the internal business process perspective. We therefore, propose the following hypothesis:
H3: Internal business process perspective has a significant influence on topaz ERP system effectiveness in HEIs

\subsection{Learning and Growth Perspective (LGP)}

This perspective according to [22] involves a question: To achieve our mission and vision, how should we sustain our ability to change and improve? Similarly, [23] explains the learning and growth perspective also in a question form as: Are we prepared for the future? Various studies [6][9][27][31] have used learning and growth perspective in the evaluation of ERP systems effectiveness.

This study has adapted the learning and growth performance indicators of [8] for the evaluation of topaz ERP systems effectiveness in HEIs. In conclusion, learning and growth perspective is a critical component for the evaluation of topaz ERP systems effectiveness in HEIs. Hence, we agree that, the effectiveness of topaz ERP systems in HEIs can be affected (evaluated) by the learning and growth perspective. We therefore, propose the following hypothesis:

H4: Learning and growth perspective has a significant influence on topaz ERP system effectiveness in HEIs

\subsection{System Quality Perspective (SQP)}

According to [11], system quality measures the information system itself. This perspective considers the quality characteristics of the system or the software. In [18], the researchers defined system quality as performance characteristics of the ERP system with regard to ease of use, accuracy, reliability, efficiency and so forth. ISO 25010 Model has been proposed to evaluate the system quality of every system (ERP systems). Various studies [4][37] have used system quality perspective in the evaluation of ERP systems.

This study has adapted the system quality measuring indicators of ISO 25010 model for the evaluation of topaz ERP systems effectiveness in HEIs. In conclusion, system quality perspective is a critical component for the evaluation of topaz ERP systems effectiveness in HEIs. Hence, we agree that, the effectiveness of topaz ERP systems in HEIs can be affected (evaluated) by the system quality perspective. We therefore, propose the following hypothesis:

H5: System quality perspective has a significant influence on topaz ERP system effectiveness in HEIs

\subsection{Effectiveness of ERP Systems (EOES)}

Effectiveness of ERP system as a construct in this study is very significant; in the sense that it is one of the construct that this research study will seek to determine its relationship with other constructs. Effectiveness of ERP system in information system concept is about goal achievement and resource utilization. The effectiveness of an IS can be defined as the extent to which an information system actually contributes to achieving organizational goals [19] [34].

This study has adapted the effectiveness of ERP systems measuring indicators of [27] for the evaluation of topaz ERP systems effectiveness in HEIs. 


\subsection{Research Framework}

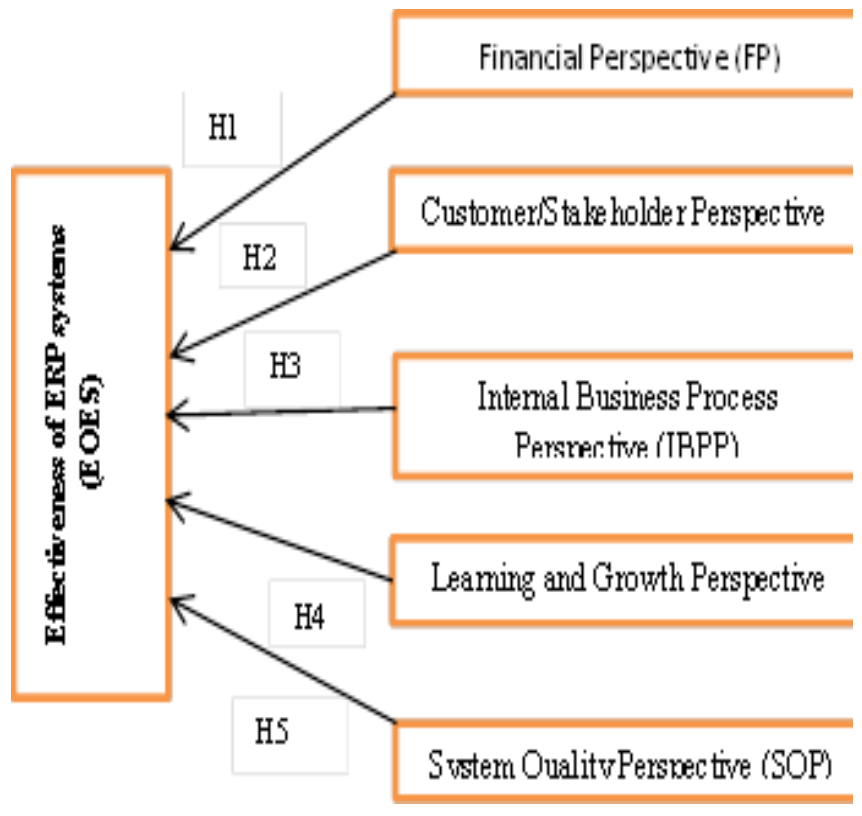

Figure 1: Proposed Analytic Framework, Source: Peters and Aggrey (2019)

\section{RESEARCH METHODOLOGY}

Since the research format is causal or explanatory research which normally test cause and effect relationship between constructs, the philosophical underpinning this study is realist assumption. Realists researchers normally test for both the qualitative and quantitative data, which they generate from a population sample and later, generate inferences from their results. The next section discusses the instrument development and data collection for this study.

\subsection{Instrument Development}

The instrument used for data collection contained scales to measure the various perspectives of the research model or framework. The research model included six constructs or variables, each of which is measured with multiple items. The questionnaire asked the respondents to rate the impact of factors (perspectives) on ERP effectiveness using 5 point likert scale with items ranged from 1 (strongly disagree) to 5 (strongly agree). Five (5) structured interview questions about the constructs were also designed to be answered by the respondents. In order to improve content validity of the instrument, these items were adapted from the literature review and experts judgment [33].

The items were reworded to reflect the context of ERP systems in higher educational sector. Also, to ensure face validity, some ERP professionals from both industry and academia were consulted; resulting in the review, reshaping and improvement in the questionnaires to the required standard.

\subsection{Measurement Instrument}

Measurement instrument used for the current research study composes six constructs and each of which is measured with multiple items (measuring indicators). Table 1 shows the constructs, their measuring items and their sources.
Table 1: Constructs, measuring items, and sources

\begin{tabular}{|l|l|l|}
\hline Constructs & $\begin{array}{l}\text { No. of Measuring } \\
\text { items/indicators }\end{array}$ & Sources \\
\hline $\begin{array}{l}\text { Financial } \\
\text { Perspective (FP) }\end{array}$ & 5 & Brown (2012) \\
\hline $\begin{array}{l}\text { Customer/Stakehol } \\
\text { der Perspective } \\
\text { (CP) }\end{array}$ & 5 & Brown (2012) \\
\hline $\begin{array}{l}\text { Internal Business } \\
\text { Process Perspective } \\
\text { (IBPP) }\end{array}$ & 5 & Brown (2012) \\
\hline $\begin{array}{l}\text { Learning and } \\
\text { Growth Perspective } \\
\text { (LGP) }\end{array}$ & 5 & Brown (2012) \\
\hline $\begin{array}{l}\text { System Quality } \\
\text { Perspective (SQP) }\end{array}$ & 6 & $\begin{array}{l}\text { ISO 25010 } \\
\text { Model (2011) }\end{array}$ \\
\hline $\begin{array}{l}\text { Effectiveness of } \\
\text { ERP Systems } \\
\text { (EOES) }\end{array}$ & 4 & $\begin{array}{l}\text { Parsa and } \\
\text { Duffchahi } \\
\text { (2015) }\end{array}$ \\
\hline
\end{tabular}

Source: Originated by the researcher

\subsection{Case Study University}

This study has adopted a case study approach to investigate the evaluation of topaz ERP systems effectiveness in HEIs. ERP systems evaluation is a phenomenon which is uncommon in higher education institutions. Despite the increasing adoption of ERP systems in HEIs, their evaluations have not well been understood. Research about ERP systems evaluations in HEIs has also been scanty. Therefore, to understand the details of ERP systems evaluations in HEIs, more case study researches are needed. This study selected University of Cape Coast (UCC) as its case study in the higher education based on the following reasons:

- Long term experiences with the use and management of topaz ERP systems, which will make the experts (respondents) to provide an objective evaluation of the system.

- To provide the researchers with rich data and information for the analysis of results.

\subsection{Sample and Data Collection}

Since ERP systems evaluations are complex and technical in nature, they need experts or people who are familiar with these systems to do data gathering. In this research study, administrators and managers of the case study university constitute the respondents. These two groups of respondents were selected because of their daily use and interactions with the ERP systems at the university. A concurrent mixedmethod sampling which comprises probability or random technique and purposive technique was used to select the respondents from the case study university. The technique helped to generate single sample for both quantitative and qualitative analysis. A total of 80 questionnaires were sent to 
the case study university (University of Cape Coast). Of the valid responses, 71 percent were males while 29 percent were females. Table 2 shows the detailed sample demographics of our respondents.

Table 2: Demographic information of the sample

\begin{tabular}{|c|c|c|c|c|}
\hline \multicolumn{5}{|c|}{ University of Cape Coast } \\
\hline Case & Correspondent & Department or Unit & System & Gender \\
\hline \multirow{5}{*}{$\begin{array}{l}\text { Case Study: } \\
\text { University of Cape Coast }\end{array}$} & $1-30(30)$ & Finance & \multirow{5}{*}{ Topaz System } & Male: \\
\hline & $31-40(10)$ & Human Resource & & $71 \%$ \\
\hline & $41-47(7)$ & Stores & & \\
\hline & $48-55(8)$ & Payroll & & Female: \\
\hline & & & & $29 \%$ \\
\hline
\end{tabular}

Source: Originated by the researcher

\section{QUANTITATIVE DATA ANALYSIS OF THE CASE STUDY}

Data collected were analyzed using the partial least square approach to structural equation modelling (PLS-SEM) on SmartPLS 3 [29]. Structural equation modelling is a powerful multivariate data analysis tool that estimates or assesses a complete model or framework through a two-step approach [10] [24]. According to the authors, structural equation models can first be examined by assessing its measurement model for reliability and validity. After the assessment of the measurement model, then followed the structural model evaluation which tests the structural paths between the latent variables in the proposed model or framework. This two-step approach to structural equation modelling is what has been used in this study to validate our research model or framework. The current study employs PLS-SEM because preliminary analysis exhibited that the data were non-normal. SmartPLS 3 is however able to handle extremely non-normal data [16]. It also performs bootstrapping analysis to help assess the statistical significance of the loadings and of the path coefficients [30]. Also the parameters of PLS approach were estimated using a resampling approach (i.e. bootstrap or jackknife) since it lacks the classical parametric inferential statistics [36].

\subsection{Case Study: University of Cape Coast Measurement model}

Measurement model in PLS-SEM can be assessed by three important psychometric properties. These are reliability of constructs, convergent validity and discriminant validity. Reliability of constructs in this study was assessed using cronbach's alpha and composite reliability measures to test for the internal consistency of the model. As displayed in table 3, each construct's cronbach's alpha and composite reliability values exceeded the acceptable level of 0.7 recommended by [25]. It can therefore, be concluded that the measurement model shows good reliability. Convergent validity of the model was also assessed based on two standards, recommended by [5]: (a) Average Variance Extracted (AVE) for each construct should exceed 0.5 [13] and (b) Indicator Factor Loadings should exceed 0.5 [15]. Table 3 once again shows evidence of convergent validity of the model. We therefore, conclude that the measurement model exhibits good convergent validity.

Discriminant validity on the other hand was assessed using the Fornell-Larcker criterion, which state that the AVE of each latent construct should be greater than the highest squared correlations between any other construct [13]. It is evident from table 4 that the square root of the AVEs for each construct is greater than the cross correlation with other constructs. Based on these results, the discriminant validity of the measurement model was established. 
Table 3: Results of reliability and convergent validity

\begin{tabular}{|c|c|c|c|c|c|c|c|c|c|}
\hline & $\mathbf{C P}$ & EOES & FP & IBPP & LGP & SQP & CA & CR & AVE \\
\hline CP1 & 0.925 & 0.568 & 0.244 & 0.579 & 0.380 & 0.326 & 0.899 & 0.928 & 0.725 \\
\hline $\mathrm{CP} 2$ & 0.733 & 0.541 & 0.437 & 0.542 & 0.427 & 0.314 & & & \\
\hline $\mathrm{CP} 3$ & 0.933 & 0.555 & 0.179 & 0.618 & 0.401 & 0.332 & & & \\
\hline $\mathrm{CP} 4$ & 0.662 & 0.409 & 0.261 & 0.580 & 0.188 & 0.294 & & & \\
\hline CP5 & 0.962 & 0.596 & 0.232 & 0.647 & 0.390 & 0.368 & & & \\
\hline EOES1 & 0.358 & 0.832 & 0.411 & 0.517 & 0.122 & 0.900 & 0.669 & 0.817 & 0.600 \\
\hline EOES2 & 0.575 & 0.693 & 0.359 & 0.463 & 0.307 & 0.388 & & & \\
\hline EOES3 & 0.590 & 0.793 & 0.493 & 0.572 & 0.507 & 0.529 & & & \\
\hline FP1 & 0.184 & 0.395 & 0.651 & 0.428 & -0.007 & 0.358 & 0.744 & 0.842 & 0.577 \\
\hline FP2 & 0.270 & 0.416 & 0.783 & 0.455 & 0.136 & 0.356 & & & \\
\hline FP3 & 0.166 & 0.297 & 0.631 & 0.197 & 0.051 & 0.186 & & & \\
\hline FP4 & 0.310 & 0.512 & 0.934 & 0.555 & 0.321 & 0.339 & & & \\
\hline IBPP1 & 0.680 & 0.539 & 0.501 & 0.865 & 0.659 & 0.302 & 0.771 & 0.866 & 0.684 \\
\hline IBPP2 & 0.499 & 0.409 & 0.426 & 0.727 & 0.251 & 0.206 & & & \\
\hline IBPP5 & 0.553 & 0.664 & 0.471 & 0.881 & 0.277 & 0.605 & & & \\
\hline LGP1 & 0.232 & 0.261 & 0.152 & 0.246 & 0.686 & 0.072 & 0.812 & 0.869 & 0.574 \\
\hline LGP2 & 0.395 & 0.299 & 0.190 & 0.459 & 0.845 & 0.109 & & & \\
\hline LGP3 & 0.269 & 0.345 & 0.196 & 0.301 & 0.696 & 0.233 & & & \\
\hline LGP4 & 0.343 & 0.184 & -0.132 & 0.298 & 0.640 & 0.047 & & & \\
\hline LGP5 & 0.393 & 0.331 & 0.191 & 0.471 & 0.890 & 0.088 & & & \\
\hline SQP1 & 0.298 & 0.710 & 0.253 & 0.345 & 0.181 & 0.879 & 0.956 & 0.965 & 0.822 \\
\hline SQP2 & 0.422 & 0.828 & 0.431 & 0.499 & 0.139 & 0.973 & & & \\
\hline SQP3 & 0.342 & 0.702 & 0.350 & 0.470 & 0.045 & 0.900 & & & \\
\hline SQP4 & 0.346 & 0.729 & 0.409 & 0.431 & 0.205 & 0.883 & & & \\
\hline SQP5 & 0.248 & 0.649 & 0.418 & 0.361 & 0.135 & 0.831 & & & \\
\hline SQP6 & 0.417 & 0.801 & 0.396 & 0.495 & 0.144 & 0.966 & & & \\
\hline
\end{tabular}

Table 4: Discriminant validity using Fornell-Larcker Criterion

\begin{tabular}{|l|l|l|l|l|l|l|}
\hline & CP & EOES & FP & IBPP & LGP \\
\hline CP & $\mathbf{0 . 8 5 2}$ & & & & \\
\hline EOES & 0.633 & $\mathbf{0 . 7 7 5}$ & & & \\
\hline FP & 0.315 & 0.544 & $\mathbf{0 . 7 6 0}$ & & \\
\hline IBPP & 0.696 & 0.667 & 0.561 & $\mathbf{0 . 8 2 7}$ & \\
\hline LGP & 0.428 & 0.387 & 0.187 & 0.476 & & \\
\hline SQP & 0.385 & 0.815 & 0.415 & 0.481 & $\mathbf{0 . 7 5 8}$ & 0.156 \\
\hline
\end{tabular}

Note: Square roots of AVE shown on diagonal and in bold, while off-diagonals are inter-construct correlations.

\section{Structural model}

In order to determine the significance of each estimated path, the bootstrapping or procedure was used with 5,000 resamples drawn with replacement. Here too, coefficient of determination $\mathrm{R}^{2}$, Stone-Geisser $\mathrm{Q}^{2}$ and standard root mean square residual (SRMR) were determined to assess the quality of the model or framework. The results for the structural model assessment are presented in table 5 and figure 2.

Financial perspective was found to have a direct significant influence on effectiveness of ERP systems with parameters $(\beta$ $=0.164, \mathrm{p}=0.046)$, thereby providing support for H1. Again, customer/stakeholder perspective was found to have a significant influence on effectiveness of ERP systems with parameters $(\beta=0.268, p=0.005)$, providing support for $\mathrm{H} 2$. Contrary to expectation, internal business process perspective was found not to have a significant influence on effectiveness of ERP systems $(\beta=0.034, p=0.731)$, providing no support for H3. Learning and growth perspective was also found not to have a significant effect on effectiveness of ERP systems with parameters $(\beta=0131, p=0.064)$, thereby providing no support for H4. System quality perspective was found to have the most significant influence on effectiveness of ERP systems $(\beta=0.607, p=0.000)$, providing support for $H 5$.

Finally, to assess the fitness of the model in PLS we used the Stone-Geisser $Q^{2}$ (predictive relevance) [14][32] and the standard root mean square residual (SRMR). $\mathrm{Q}^{2}$ is a measure of how well the observed values are reproduced by the model and its estimated parameters. $\mathrm{Q}^{2}$ value greater than 0 is an indicative of predictive relevance. The $\mathrm{Q}^{2}$ value for effectiveness of ERP systems in this model is 0.424, indicating predictive relevance. The SRMR value for the model was also found to be 0.069 , which is far below the 0.08 threshold recommended by [17]. Therefore, the model presents a good model fit.

Table 5: Path coefficients and their significance 


\begin{tabular}{|l|l|l|l|l|l|}
\hline Hypotheses & Path & $\begin{array}{l}\text { Standard path } \\
\text { coefficient }\end{array}$ & $\begin{array}{l}\text { T } \\
\text { Statistic }\end{array}$ & Value & Result \\
\hline H1 & FP $\rightarrow$ EOES & $0.164^{*}$ & 1.994 & 0.046 & Supported \\
\hline H2 & CP $\rightarrow$ EOES & $0.268^{* *}$ & 2.800 & 0.005 & Supported \\
\hline H3 & IBPP $\rightarrow$ EOES & $0.034 \mathrm{~ns}$ & 0.344 & 0.731 & Not Supported \\
\hline H4 & LGP $\rightarrow$ EOES & $0.131 \mathrm{~ns}$ & 1.851 & 0.064 & Not Supported \\
\hline H5 & SQP $\rightarrow$ EOES & $0.607^{* * *}$ & 9.149 & 0.000 & Supported \\
\hline Coefficient of determination R ${ }^{2}$ & & & & 0.827 \\
\hline Stone-Geisser Q & & & & & 0.424 \\
\hline SRMR & & & & & 0.069 \\
\hline
\end{tabular}

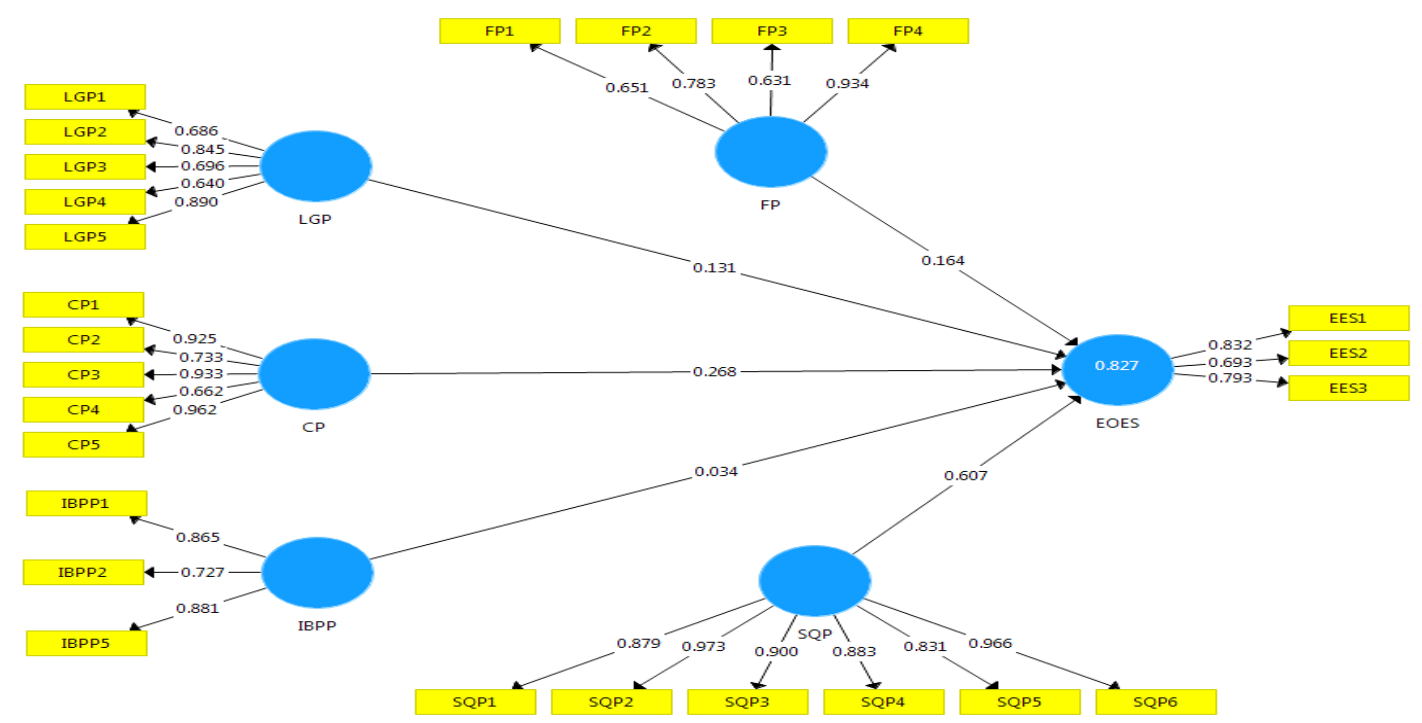

Figure 2: PLS results for structural model (University of Cape Coast)

\section{QUALITATIVE DATA ANALYSIS OF THE CASE STUDY}

Data collected by qualitative method (interviews) were analyzed using inductive thematic analysis. According to [7] thematic analysis is "a method for identifying, analyzing and reporting patterns within data". Inductive thematic analysis was chosen by the researchers to help derive meaning from the patterns of qualitative data set to enhance and validate results of the quantitative analysis.

\subsection{Case Study: University of Cape Coast}

Topaz software system is the ERP system used by the University of Cape Coast. Topaz ERP system integrates both the finance and human resource departments of the university and has been implemented for the past three years. The interview with administrators and managers focused on the following specific points or themes:

\section{Financial perspective of topaz ERP systems effectiveness}

One of the key benefits of implementing ERP systems at higher education is its ability to manage financial aspects or activities of that institution. According to the administrators, the university acquired the topaz ERP system to consolidate all their accounts preparations. They stated that the topaz system has helped to manage investment portfolios, management reporting and financial reporting:

Topaz system has really enabled the university to manage its investment portfolios, generate management and financial reports as and when needed by the management (Managers).

The administrator also interviewed asserted that topaz system has helped reduced cost of operations, managed students fees payments and detections of financial omissions such as overpayments and underpayments of certain goods and services:

Topaz system has helped us to reduce cost of operations, manage student's fees payments and detections of financial omissions such as overpayments and underpayments of certain goods and services (Administrators)

Customer/Stakeholder perspective of topaz ERP systems effectiveness 
ERP systems come with great benefits to its stakeholders such as students, academic and non- academic staff, governments and affiliate institutions. According to the managers, topaz system has helped the university to prepare and deliver all its financial and human resource management reports to government for decision-making. The managers also pointed out that, even though the topaz system does not have a direct link to government system (controller and accountant general department system), it is still able to generate and deliver the information needed.

Even though the topaz system does not have a direct link to government system (controller and accountant general department system), it is still able to generate and deliver the information needed by government for decision-making (Managers)

The staffs of the university (academic and non-academic staff) do not have the direct use of the topaz system; they only receive their electronic payslips from the system through their email addresses (Administrators).

\section{Internal business process perspective of topaz ERP systems effectiveness}

Because the topaz system is not a web-based system, working remotely is a challenge since you cannot access the system anywhere to do your work. To work with the topaz system you must have a connection to the server hosting the software system or you must have the software system installed on your computer (Managers).

We sometimes experience network connection problems to the system, making it difficult to complete most of our job processes and activities. Again, we sometimes experience slow response to the topaz system (Administrators).

\section{Learning and growth perspective of topaz ERP systems} effectiveness

Training and development is important for every staff member of the university. For that matter, the managers stated that users of the topaz system need short training courses that will enable them to be effective in their job:

Initially, topaz system came with its documentations to help users to learn how to use the system; however, due to customizations to the system, these documentations have been rendered useless or redundant. Support to the system sometimes takes time to come, creating delays to most of the processes and activities of the university (Managers).

Vendor training was done for us initially after the system was implemented, but since that time no other training and development section has been organized for us. We need short training courses to develop our capabilities on the use of the system (Administrators).

\section{System quality perspective of topaz ERP systems effectiveness}

Most information systems are effective because their system qualities or features can be used to achieve their purpose or goals. The managers stated that topaz system came with several features that have really helped to achieve its effectiveness.
Topaz systems are more user-friendly, easy to learn and easy to navigate your way through. It is not a complex and difficult software system to learn and use. It comes with a simple graphical user interface (GUI) that can easily be used (Managers)

With topaz system our data and information are well secured from intruders. The system comes with strong security features that have prevented many people from getting into the system through backdoor. The only challenge to topaz system quality is the absent of web-interface module (Administrators)

\section{DISCUSSIONS AND IMPLICATIONS}

Studies that examine ERP systems effectiveness have all been done in the context of business organizations. By examining the determinants of topaz ERP systems effectiveness in the Ghanaian higher education, we add new insight into the existing literature by offering a better theoretical understanding of ERP systems effectiveness in general. Although the Ghanaian higher education is rapidly adopting and implementing ERP systems, very little is known about their effectiveness evaluations. In this regard, our study extends knowledge on ERP systems effectiveness evaluation in the context of Ghanaian higher education. The study examines the influences of financial perspective, customer/stakeholder perspective, internal business process perspective, learning and growth perspective and system quality perspective on topaz ERP systems effectiveness in Ghanaian higher education. A case study was conducted and five (5) relationships with the study's constructs were hypothesized and tested with PLS-SEM.

From the quantitative analysis, three (3) of the hypothesized paths were supported and two (2) were rejected. These results were in consistent with our qualitative analysis results and also with the work done by [27]. The implications of these results suggest that ERP systems effectiveness in the university is greatly influenced by financial, customer/stakeholder and system quality perspectives. For that matter, the university must continue doing its best to maintain and improve these perspectives of the system. Again, these results also imply that the university is not achieving effectiveness of ERP systems in the internal business processes; and learning and growth perspectives. This is in partial support of the work done by [27], who stated that internal business process perspective has the greatest impact while learning and growth perspective has the least impact. In summary, the ERP system (topaz system) of the university has been successfully evaluated and has proved effective with our research model.

\section{LIMITATION AND FUTURE RESEARCH DIRECTIONS}

Despite the study's interesting findings and implications, it is not without limitations. These limitations, however, present directions and opportunities for future research. First, this research included only five specific factors based on prior research works. There may be additional factors which determine or influence ERP system effectiveness in HEIs that were not examined in this study. Secondly, there are other evaluation models or frameworks that can be integrated to study ERP systems effectiveness in HEIs. Thirdly, crosssectional and longitudinal surveys can also be used to study the effects of these constructs on ERP systems effectiveness in HEIs. Lastly, we suggest researchers investigate ERP 
systems effectiveness in HEIs by comparing results from developed nation to developing nation.

\section{ACKNOWLEDGMENTS}

This is to acknowledge the grace and mercy of GOD for His enablement, continual guidance and assistance. We are also grateful to all those who one way or the other contributed to the success of this research study.

\section{REFERENCE}

[1] Abugabah, A. \& Sanzogni, L. (2010). "Enterprise Resource Planning (ERP) System in Higher Education: A literature Review and Implications", International Journal of Human and Social Sciences, 5 (6): pp. 395 399.

[2] Abugabah, A.; Sanzogni, L. \& Osama, A.A. (2013) "The Phenomenon of Enterprise Systems in Higher Education: Insights From Users", International Journal of Advanced Computer Science and Applications. Vol 4, No 12

[3] Alimoradi, Z., (2012) "Assessment of the effectiveness of ERP systems by a Fuzzy logic approach", Journal of Information Technology Management, Volume XXIII, Number 4, 2012.

[4] Althonayan, M. (2013) "Evaluating Stakeholders Performance of ERP Systems in Saudi Arabia Higher Education", Ph.D. Thesis, Department of Information Systems and Computing, Brunel University.

[5] Bagozzi, R.P., and Yi, Y. (1988) "On the evaluation of structural equation models", Journal of the Academy of Marketing Science, 16(1), 74-94.

[6] Batada, I. and Rahman, A. (2012) "Measuring System Performance \& User Satisfaction after Implementation of ERP", Proceedings of Informing Science \& IT Education Conference (In SITE)

[7] Braun, V. and Clarke, V. (2006) "Using thematic analysis in psychology", Qualitative Research in Psychology, 3, pp.77-101.

[8] Brown, C. (2012) "Application of the Balanced Scorecard in Higher Education opportunities and Challenges", An evaluation of balance scorecard implementation at the College of St. Scholastica.

[9] Chang, H. H. (2008) "Intelligent agent's technology characteristics applied to online auction' task: A combined model of TTF and TAM", Technovation, 28, pp. 564-577.

[10] Chin, W.W., (1998) "The partial least squares approach to structural equation modeling", Modern Methods for Business Research, 295(2), 295-336.

[11] Delone, W.H. and Mclean, E.R. (1992) "Information systems success: The quest for the dependent variable", Information systems research, 3 (1), pp.60-95.

[12] Fahmy, S. Haslinda, N. Roslina, W and Fariha, Z. (2012). "Evaluating the Quality of Software in e-Book Using the ISO 9126 Model". International Journal of Control and Automation Vol. 5, No. 2.

[13] Fornell, C. and Larcker, D.F. (1981), "Evaluating structural equation models with unobservable variables and measurements error", Journal of Marketing Research, Vol. 18, Feb, pp. 39-50.

[14] Geisser, S. (1975) "The predictive sample reuse method with applications", Journal of the American Statistical Association, Vol. 70 No. 350, pp. 320-328.

[15] Hair, J.F., Black, W.C., Babin, B.J., Anderson, R.E., \& Tatham, R.L. (2006). "Multivariate data analysis, New Jersey, NJ: Prentice Hall.
[16] Hair, J.F., Hult, T.M., Ringle, C. and Sarstedt, M. (2014). "A Primer on Partial Least Squares Structural Equation Modeling (PLS-SEM), Sage Publications, Thousand Oaks, CA.

[17] Hu, L. and Bentler, P.M. (1999). "Cutoff criteria for fit indexes in covariance structure analysis: conventional criteria versus new alternatives", Structural Equation Modeling: A Multidisciplinary Journal, Vol. 6 No. 1, pp. 1-55.

[18] Ifinedo, P., Birger, R., Ifinedo, A., and Sundberg, K. (2010) "Relationships among ERP post implementation success constructs: an analysis at the organizational level," Computers in 630 Human Behavior, vol. 26, no. 5, pp. $1136-1148$

[19] Ifinedo, P., 2011. "Examining the influences of external expertise and in-house computer/IT knowledge on ERP system success". Journal of Systems and Software 84, 2065-2078.

[20] ISO/ IEC CD 25010 (2008) "Software Engineering: Software Product Quality Requirements and Evaluation (SQuaRE) Quality Model and guide”. International Organization for Standardization, Geneva, Switzerland.

[21] Kaplan, R. S. (2010) "Conceptual Foundations of the Balanced Scorecard". Harvard Business School Accounting \& Management Unit Working Paper No.10074.

[22] Kaplan, R. S., and Norton, D. P (1992) "The Balanced Scorecard: Measures that drive performance". Harvard Business Review, pp. 172-180.

[23] Kaplan, R. and Norton, D.P. (1996) "The balanced scorecard: translating Strategy into Action. Boston": Harvard Business School Press.

[24] Kelloway, E. (1998). "Using LISREL for structural equation modeling: A researcher's guide", Sage Publications, Inc.

[25] Nunnally, J. and Bernstein, I. (1994). "Psychometric Theory”, 3rd ed., McGraw-Hill, New York, NY.

[26] Panorama ERP Report, 2016

[27] Parsa, K. and Duffchahi, N. (2015) "Evaluating the effectiveness of enterprise resource planning (ERP) system to improve managers' decision-making through balanced scorecard approach", Journal of Applied Environmental and Biological Sciences

[28] Peters, E., \& Aggrey, G. K. (2019, March). "Evaluating the Effectiveness of ERP Systems in HEIs: A Proposed Analytic Framework". In 2019 International Conference on Computing, Computational Modelling and Applications (ICCMA) (pp. 40-45). IEEE.

[29] Ringle, C.M., Wende, S. and Becker, J.M. (2015). "SmartPLS 3. Boenningstedt: SmartPLS GmbH", available at: www.smartpls.com

[30] Ringle, C. M., Wende, S. \& Will, A. 2005. SmartPLS 2.0.M3 (beta), Hamburg, University of Hamburg.

[31] Shen,Y., Chen,P., Wang, C. (2016) "A study of enterprise resource planning (ERP) system performance measurement using the quantitative balanced scorecard approach", Computers in Industry 75 (2016) pp.127139

[32] Stone, M. (1974), "Cross-validatory choice and assessment of statistical predictions", Journal of the Royal Statistical Society. Series B (Methodological), Vol. 36 No. 2, pp. 111-147.

[33] Straub, D., Boudreau, M.C. and Gefen, D. (2004), "Validation guidelines for IS positivistic research", Communications of the Association for Information Systems, Vol. 13 No. 1, pp. 380-427. 
[34] Thong J.Y.L., Yap,C. \& Raman, K.S. (1996). “Top Management Support, External Expertise and Information Systems Implementation in Small Businesses". Information Systems Research, 7(2), pp. $248-267$.

[35] Topaz Solutions: www.topaz.nz

[36] Wold, H. O. A. (1982), "Soft modelling: The basic design and some extensions. In K. G. Joreskog, \& H.O.A. Wold (Eds.), Systems under indirect observation. Causality, structure, prediction: Part II (pp. 1-54). Amsterdam: North-Holland.

[37] Zare, A. and Ravasan, A.Z. (2014) "An Extended Framework for ERP Post-Implementation Success Assessment", Information Resources Management Journal, 27(4), pp.45-65, October-December 2014.

\section{APPENDIX}

Financial Perspective (FP) and Indicators: Adapted from Kaplan (2010) and Brown (2012)

1. The topaz ERP system has helped us to reduce cost of operations

2. The topaz ERP system has helped to facilitate enrollment growth of the university

3. The topaz system has assisted us to manage our investments and assets

4. The topaz system has brought tremendous efficiency in our financial and management reporting

5. Donations from alumnus and donor partners have been facilitated by the topaz system

Customer/Stakeholder Perspective (CP) and Indicators: Adapted from Kaplan (2010) and Brown (2012)

1. The topaz system has assisted students to register courses online, check their results and assess their lecturers

2. The topaz ERP system has helped students to graduate on time without any backload of students

3. The topaz system has helped to optimize learning experiences among students

4. Relationships with the government and affiliate institutions have been improved with the topaz ERP

5. Topaz ERP system has enabled staff members to check their payroll information, apply for leave, apply for promotions and retirement issues

Internal Business Process Perspective (IBPP) and Indicators: Adapted from Kaplan (2010) and Brown (2012)

1. The topaz system has assisted us to create new innovative programs and activities

2. The topaz system has improved processes and activities leading to the delivery of information

3. Students support network has been strengthened with the topaz ERP systems

4. With the topaz ERP system, multiple tasks can be handled and to generate different formats of report

5. Topaz ERP systems help in the internal communications among various units or departments

Learning and Growth Perspective (LGP) and Indicators: Adapted from Kaplan (2010) and Brown (2012)
1. With the topaz ERP system use in the university, various qualified faculty and staff members have been retained

2. The topaz system supports faculty professional practice and research

3. The topaz system comes with easy documentations and supports

4. The topaz system has helped me to learn excel, access and other software applications to develop my skills

5. Topaz ERP system has assisted to improve and manage information technology (IT) infrastructure

System Quality Perspective (SQP) and Indicators: Adapted from Kaplan (2010) and Brown (2012)

1. The topaz ERP system provides security to our data and information

2. in the event of any disaster, data and information can easily be recovered

3. It is easy to learn and use the topaz ERP system

4. Time and effort are not wasted in the topaz system

5. Changes or modifications can be made in the topaz system without affecting or introducing defects into the system

6. The topaz system can easily be moved to different hardware platforms or environments for other operations

Effectiveness of ERP System (EOES) and Indicators: Adapted from Parsa and Duffchahi (2015)

1. Topaz ERP system makes information available to its users

2. Topaz ERP system helps to integrate processes within the organization or the institution

3. The topaz system prevents parallel or similar operations of activities within the organization or the institution

4. Topaz ERP system prevents entering of duplicate records of data and information 